\title{
1. Platforms, markets and innovation: an introduction
}

\section{Annabelle Gawer}

\section{INTRODUCTION}

The emergence of platforms, whether used inside firms, across supply chains, or as building blocks that act as engines of innovation and redefine industrial architectures, is a novel phenomenon affecting most industries today, from products to services. This book, the first of its kind dedicated to the emerging field of platform research, presents leading-edge contributions from top international scholars from strategy, economics, innovation, organizations and knowledge management.

This book represents a milestone for the vibrant field of platform research. It is the outcome of an ambitious international collaboration, regrouping and making connections between the research work of 24 scholars, affiliated with 19 universities, in seven countries over four continents. The novel insights assembled in the 14 chapters of this volume constitute a fundamental step towards an empirically based, nuanced understanding of the nature of platforms and the implications they hold for the evolution of industrial innovation.

But what exactly are platforms? Why should we care about them? And, why do we need a book about them?

\section{WHY THIS BOOK?}

We find platforms in many industries, and certainly in all high-tech industries. Google, the Internet search engine, social networking sites such as Facebook, operating systems in cellular telephony, videogame consoles, but also payment cards, fuel-cell automotive technologies and some genomic technologies are all industry platforms. But perhaps the most media-covered platform (and archetypal example) is Microsoft Windows. Windows is also a great example of just how much we still don't understand about platforms. 
The two highly publicized antitrust lawsuits brought against Microsoft by the US Department of Justice and the European Commission have given rise to unprecedented levels of fines, in the hundreds of millions of US dollars, and have revealed profound differences in the opinions held by, on the one hand, the firms involved, and on the other by the regulatory authorities. The disagreements did not stop there: the US and European regulatory authorities upheld very different rulings. In fact, very few experts agreed with each other in the course of these lawsuits, which have been the setting for highly contradictory arguments not only between managers and technologists of opposite camps - which was to be expected - but also between world-class scholars. Leading-edge economists and management scholars, in particular, have publicly taken radically different stands as to whether Microsoft's business practices were anticompetitive.

A central issue addressed in the lawsuits was the potentially adverse effect that certain business practices from Microsoft, a dominant firm in the operating systems market, could have on competition, industry innovation and social welfare. The controversial practices ranged from Microsoft's decision to bundle its Windows software with complementary products to its decision to withhold information on how to connect complementary products to Windows. The theoretical disagreement between economists was particularly noticeable, as, at least in principle, they based their logic on the same economic theory. What was the root of the problem?

Microsoft Windows is an industry platform - a building block, providing an essential function to a technological system - which acts as a foundation upon which other firms can develop complementary products, technologies or services. As a platform, it is subject to so-called network effects, which tend to reinforce in a cumulative manner early gained advantages such as an installed base of users, or the existence of complementary products. In a positive feedback loop, new users get more benefit from using Windows than from using an alternative platform, as it is already installed on many personal computers (PCs) and therefore facilitates exchange of files and interoperability in general. They also benefit from a sizeable pool of existing Windows-compatible software, which makes Windows more useful. Software developers wishing to develop new software applications will find that, when deciding whether to make such new applications compatible with an alternative platform, they will be better off designing for Windows, as most developers have done, since it already has a large installed base of users.

The cumulative nature of these network-fuelled dynamics implies that those platforms that make it past a certain tipping point tend to become really hard to dislodge. In a sense, as platforms' market share grows, so 
also grow their own barriers to entry. The extreme dominance of firms such as Microsoft, and more recently of Google, is unprecedented. The speed of innovation these firms have conducted, as well as the intensity and speed of innovation conducted in the industries (some prefer the word ecosystem) they operate in, is also unprecedented. And all this is happening, with real-life consequences of enormous proportions, while many observers, managers, regulators or scholars are still coming to terms with the different facets of platforms, and trying to make sense of them. The unresolved differences between the economists mentioned above also invite us to look more deeply into this phenomenon, as it point to the limits of our existing knowledge and understanding. It is the contention of the authors of this book that, with platforms, we are facing a situation where existing theory is reaching its limits. As scholars, we felt that we collectively needed to push our understanding of this multifaceted phenomenon forward, with an inquisitive and open mind, but based on rigorous research and facts.

The emerging phenomenon of platforms affects industrial dynamics, creates new forms of competition, reveals new forms of collaborative innovation across firms and poses a host of new fundamental questions. These new questions include, but are not limited to, social welfare questions, industry dynamics questions and strategy questions. There are also questions about the management and the design of platforms, their impact on international competition, as well as their implications for an economy of services.

Citizens, consumers and regulators care about social welfare questions, such as: how can consumers enjoy the benefits from innovation created by dominant platform firms without letting this dominance get out of control? How can we achieve a more nuanced understanding of the respective impact of competition and of inter-firm collaboration, and particularly of collaborative innovation, on social welfare? For example, how can we assess the possible tradeoffs between benefits from competition and benefits from innovation? How do we evaluate tradeoffs between innovation on the platform, performed by platform owners, and innovation on complements or modules, performed by complementors? What kinds of platform governance should be put in place to ensure the best functioning of platforms and ecoystems?

Then we have a set of industry dynamics questions: under which conditions can we expect industry platforms to emerge? What forms do they take, in what context? And then, there are of course the strategic questions, which are the ones managers and investors care about, as they are linked to firms' performance: how can firms succeed in the new platform game? Which capabilities are needed? When should firms open up their technologies and processes, or when should they adopt proprietary strategies? Is 
there a continuum between 'open' and 'closed'? How do we know which strategy is best, given our industry's and firm's circumstances?

Last, there are questions related to the management and design of platforms, as well as questions about implications for international competition and division of labour. For example: how to manage the exploratory processes to create a platform? How to manage platform development projects? How to manage the creation of knowledge associated with the collective innovation practices? And, last but not least, what are the implications of all of this for competition and innovation in services? This book uncovers many such questions - and offers some answers.

As the editor of this book, I would say that if there was one idea that I wish readers would take away with them as they start thinking seriously about platforms, and about what is unique about them, it would be the following: platforms invite us to examine carefully the intimate interactions between technology and business, and in particular between the structure of technology and the modalities of business interaction. If this book manages to identify and highlight these interactions, it will have presented a persuasive argument for why we cannot afford to take technology as static, monolithic, exogenous, or as simply the precinct of engineers. That will be a major achievement, as it runs against not only common practice within organizations, but also entrenched intellectual reflexes within academia.

Sometime towards the end of the nineteenth century, the modern industrial firm was born, and with it came a new separation into distinct spheres of the engineers on the one hand, with their instruments, language and knowledge, focusing on creating products, and the business managers on the other, focusing on clients, transactions and markets. As those of us who have worked in firms know from experience, these people talk different languages, and in many organizations don't really talk to each other. Further, the separation of these spheres has also been found in academia. The economists of the twentieth century could relatively safely assume technology away in their models as a mere production function, and many management scholars have done so too. Markets and industries have been assumed to exist, products have been assumed to exist, and their uses were assumed to be known as well: all of these (industries, markets, products and uses) have accustomed us to expect some degree of stability. Therefore questions such as 'Where will market transactions take place?', and 'What will be the nature of these transactions?', had rather obvious answers.

However, when one observes the constantly evolving nature of platforms such as Windows or Google, it seems that their owners are not just part of one industry (computing), but instead able to enter seamlessly into other markets such as cellular telephony or media content. While the 
content and the uses of the platform product change constantly, one realizes that some of our old assumptions simply don't hold. We shall have to think about what it is in the structure of the technology (which we can also call its architecture) that facilitates or hinders the emergence of new markets and new types of transactions. One of the points of contention of Microsoft and of the economists on its side was to object, on the basis of principle, that no regulator should have the right to intervene in product design. ${ }^{1}$ This claim seems obvious and legitimate to many economists: the design of the product should be the prerogative of the firm! However, when product design (which is, precisely, the domain of technology structuring and architecture), in the hands of a dominant firm, affects the sheer possibility of existence of markets, then perhaps the regulator should be allowed to have a look - and a say.

But of course then we enter uncharted territory - where we cannot assume that collaboration between firms is necessarily a price-fixing, colluding endeavour, and where competition and collaboration each play a role less simple than we have been used to. Where the regulator was understood to be the guarantor that competition would be free to play its course, we now face situations when, if unchecked, competition can create adverse conditions for innovation and for consumers. Again, this is uncharted territory, and this is precisely why we need rigorously derived, preferably empirically based, new knowledge that addresses these new issues head on. This book attempts to do just that.

\section{OBJECTIVES OF THIS BOOK AND HOW IT CAME TO EXIST}

I conceived of this project because I realized that, over the past ten years or so, since I completed my doctoral work on platform leadership (Gawer, 2000) and published my first book on the topic with Michael Cusumano (Gawer and Cusumano, 2002), many individual researchers had made remarkable progress, each in his or her field, that could contribute towards a better understanding of the multifaceted phenomenon of platforms. It appeared to me that there was an as-yet-unrecognized community of researchers working in different universities and using different approaches, a few of whom knew each other (or each other's work). There were also others who did not know each other, but would certainly benefit if they were put in contact.

I discussed my project with publisher Edward Elgar, and his early personal support and commitment were invaluable. It was most rewarding that the great majority of book contributors I had in mind responded 
enthusiastically to my invitation to write a chapter either individually or as a team. As my intention was not only to stimulate new research in this field by offering a publication opportunity to these top researchers, but also to contribute as much as possible to the advancement of the field, I thought of a way for these diverse researchers to enrich their own thinking by incorporating each other's insights into their own chapters. I conceived therefore of organizing a conference, to take place roughly mid-course between the time researchers started to work on their chapter and the delivery date of the manuscript, and so, crucially, at a time when they would be actively engaged in the writing process. The objective of this conference was to give each book contributor an opportunity to get feedback from fellow contributors - as well as to learn from their presentations - at a time that was propitious for these insights to be reflected in the end result. As each chapter can be seen as a module of the overall book, this conference aimed to increase the integration of the chapters, to achieve an output whose quality would be better than the sum of its parts.

The first international conference on Platforms, Markets and Innovation took place in June 2008 at Imperial College Business School, London, my home institution, and was a great success. It featured the book contributors, from all over the world, who presented and/or discussed the working chapters to/with each other and to an 80 -strong audience of other researchers, managers and students. It also featured a panel discussion between researchers and top executives from IBM, Intel, Microsoft and British Telecom. The conference was also an opportunity for this new community of researchers to meet in one place and get to know each other. Many authors confirmed - and I can testify - that most chapters benefited from this group discussion.

For readers who are familiar with how platforms work, they will have recognized in the vision and the design of this book several themes that are part of platforms thinking, and that are dear to my heart: creating a platform, stimulating others to innovate towards the collective creation of an output that is better through coordination, while preserving individual incentives.

\section{CONTENT OF THIS VOLUME}

The book comprises 14 chapters, and is divided into three parts. Part I presents an overview of platforms. Part II focuses on specific questions related to opening or closing platforms, as well as on platform governance issues. Part III focuses on platform management, design and knowledge issues. 
Chapter 1, this Introduction, situates the book and summarizes its content.

In Chapter 2, Carliss Y. Baldwin and C. Jason Woodard set an ambitious agenda: to present a unified view of platforms, cutting across the different streams of literature (product development, technology strategy and industrial economics) in which the term has been used. Their chapter aims to shed light on the relationships between platforms and the systems in which they are embedded, in order to better understand firms and industries where platforms play an important role. The authors define a platform as a set of stable components that supports variety and evolvability in a system by constraining the linkages among the other components. Although the term 'platform' is used in diverse ways that seem difficult to reconcile, Baldwin and Woodard find that the fundamental architecture behind all platforms is essentially the same: the system is partitioned into a set of 'core' components with low variety and a complementary set of 'peripheral' components with high variety. The low-variety components constitute the platform. They are the long-lived elements of the system and thus implicitly or explicitly establish the system's interfaces, the rules governing interactions among the different parts. This underlying architectural unity motivates the authors' effort to develop a common set of analytical tools for studying platforms and the industries that produce them. Among the most important tools are representation schemes - in other words, ways to draw pictures of platform architectures. The authors discuss approaches from three different literatures: network graphs from organization theory; design structure matrices from engineering design; and layer maps from technology strategy. The chapter concludes by addressing four questions: first, when is a platform architecture preferable to allowing all components to vary arbitrarily? Second, when can a platform and its peripheral components (complements) remain within the control of a single firm? Third, when should a firm allow or encourage outsiders to develop complements to a platform it controls? And fourth, if a firm does allow - or is forced to accept - external complementors, over which components of the system should it strive to retain control?

In Chapter 3, I aim to answer two research questions: (1) under which conditions can we expect industrial platform dynamics to emerge and unfold? (2) In the context of platform industry dynamics, what kind of platform strategies should firms devise, depending on whether they are incumbents or new entrants? To answer to the first question, I set out to present a new typology of platforms, which identifies the context in which different types of platforms appear. Platforms are designed and used in three main settings: inside firms; across supply chains; or as industry platforms - when they are the building blocks that act as engines of innovation 
and redefine industrial architectures. I then suggest an 'evolutionary perspective on platform emergence', and identify circumstances under which internal platforms evolve into supply chain platforms, which then evolve further into industry platforms. To answer the second question on platform strategies, I build on Gawer and Cusumano's (2008) concepts of 'coring' and 'tipping', and further specify the combinations of these that should be best suited to new entrants and to incumbents, depending on characteristics of the industry they operate in or wish to enter. I also suggest that firms' 'design capabilities' (i.e. whether a firm's design capability is to be an integrator/system assembler or a specialist/component maker) should have a decisive impact on which strategy to pursue. I conclude with implications and further questions for the study of platforms in services.

In Chapter 4, Fernando F. Suarez and Michael A. Cusumano examine a fascinating but as-yet-understudied aspect of platforms emergence and competition: the role of services. They note that the platform literature has grown out of innovation and new product development studies, which have tended to overlook the role of services. The authors focus on three questions: what is the potential role of services in the outcome of platform battles in product industries? What is the importance of services in platform-mediated markets versus other markets? And which types of firms are more likely to produce services in platform-mediated industries and why? The authors identify several roles that services play: first, they can be used to facilitate adoption, either by lowering adoption risk or through subsidy. Second, delivering services implies a close interaction with consumers, which provides useful feedback for further platform innovation. Third, the authors offer several examples where services enhance the value of the platform through a variety of indirect network effects, and can also act as customer retention mechanisms. In the empirical part of their chapter, Suarez and Cusumano observe that in the software products industry, platform markets such as operating systems, multimedia, and videogames, services revenues do not overtake product revenue - suggesting that this may be caused by the resilience of platform markets to commoditization. Last, the authors discuss circumstances under which the platform firms are likely to provide the services themselves rather than through a network of external service providers.

In Chapter 5, David S. Evans explores how entrepreneurs who start multi-sided platforms must secure enough customers on both sides, and in the right proportions, to provide enough value to each group of customers and to achieve sustainable growth. Evans's chapter, precisely because it focuses on the problem faced by start-up entrepreneurs who have to 'ignite' markets, is an important and welcome contribution to the 
literature on multi-sided platforms - which have so far tended by and large to assume that the markets on each side of the platform already exist, and have focused almost exclusively on how to price access to the platform to encourage adoption. In Evans's chapter, the entrepreneurs must secure 'critical mass' to ignite the growth of their platforms, otherwise their platform implodes. The chapter details a number of strategies available to entrepreneurs to reach this critical mass. These include the 'zig-zag' which involves successive accretions of customers on both sides to build up the value to both sides - and the 'two-step' - which involves getting enough members of one side on board first and then members of the other side. These strategies can usefully employ many of the tactics used for new product introductions by non-platform businesses. The relevant strategies depend in large part on whether the nature of the platform requires securing participation by both platform sides at launch, as is the case with dating venues; whether it is possible to acquire one side before approaching the other side, as is the case with search engines; and whether it is necessary to make pre-commitments to one side to induce them to make investments, as is the case with videogames. The chapter concludes with an analysis of two sets of examples: B2B (business-to-business) exchanges, and social networking websites Friendster and Facebook.

Part II focuses on specific questions related to opening or closing platforms, as well as on platform governance issues.

In Chapter 6, Thomas R. Eisenmann, Geoffrey Parker and Marshall Van Alstyne offer a systematic and rigorously derived set of strategies and guidelines for managers on how to make the right choices about opening or closing mature platforms. Selecting optimal levels of openness is crucial for firms that create and maintain platforms. Decisions to open a platform entail tradeoffs between adoption and appropriability. Opening a platform can spur adoption by harnessing network effects, reducing users' concerns about lock-in, and stimulating production of differentiated goods that meet the needs of user segments. At the same time, opening a platform typically reduces users' switching costs and increases competition among platform providers, making it more difficult for them to appropriate rents from the platform. The authors focus on a subset of platforms: those that exploit network effects by mediating transactions between platform users. The conclusions from this chapter are the following: platform openness occurs at multiple levels depending on whether participation is unrestricted at the (1) demand-side-user (end-user), (2) supply-side-user (application developer), (3) platform provider or (4) platform sponsor levels. These distinctions in turn give rise to multiple strategies for managing openness. Horizontal strategies for managing openness entail licensing, joint standard setting and technical interoperability with rival platforms. 
Vertical strategies for managing openness entail backward compatibility, platform and category exclusivity, and absorption of complements. Each strategy grants or restricts access for one of the four platform participants. When proprietary platforms mature, they are often opened to encompass new providers. Once network mobilization winds down and free-rider problems are no longer salient, proprietary platform sponsors may find it attractive to license additional providers to serve market segments with diverse needs. Naturally, these new providers will seek a say in the platform's direction: they will try to force a previously proprietary platform to open its governance. Likewise, as shared platforms mature, their renewal may hinge on partners ceding power to a central authority that can set priorities and settle disputes over who will provide next-generation technologies. This closes the governance of a previously open platform. Thus forces tend to push both proprietary and shared platforms over time towards hybrid governance models typified by central control over platform technology and shared responsibility for serving users.

In Chapter 7, Kevin J. Boudreau and Andrei Hagiu make an important contribution to the literature on multi-sided platforms by focusing on the importance and variety of non-price instruments plaform owners use to regulate and govern their platform. Multi-sided platforms (MSPs) are characterized by interactions and interdependence between their multiple sides, and the existence of network effects. The thrust of prior work in the MSP literature has focused on the question of how to get the different sides around an MSP 'on board' in large numbers, while setting up a pricing model that maximizes platform profits. Overall, the MSP literature has emphasized arm's-length pricing as the central strategic instrument used by platform owners to intermediate the ecosystem of users and complementors surrounding an MSP. A number of provocative analyses, however, have suggested a richer picture of the role of MSPs and limitations to arm's-length market interactions. Metaphors of 'open' and 'closed' platforms convey something of how restrictive or liberal a platform may be in its dealings with surrounding constituents. But also, several studies have documented a variety of roles played by platform owners, including ensuring 'coherent' technical development and coordination among contributors to an MSP ecosystem; designing the technical architecture that frames interaction; encouraging complementors to make investments; and generally 'managing' and 'maintaining the health' of the ecosystem, such as by using the non-price levers such as the 'four levers of platform leadership' which include: firm boundaries and internal organization of the platform owner, product technology and relationships with platform participants. The nature of these activities clearly goes beyond governing economic activity solely within the boundaries of platform 
owners and extends to rule making and regulating the conduct of firms beyond their economic boundaries, as suggested by several authors, who characterize MSPs as a 'licensing authority' that 'regulates connections among ecosystem members' so as to 'increase diversity and productivity'; or go as far as to speculate that 'the monopolist [platform owner] plays a role like that of a "public interest" regulator'. The primary contribution of Boudreau and Hagiu's chapter is to present evidence supporting these notions of a regulatory role of MSPs that goes well beyond price setting and includes imposing rules and constraints, creating inducements and otherwise shaping behaviours. These various non-price instruments essentially solve what would otherwise be (multi-sided) 'market failures'. The authors use four primary case studies to illustrate these points. Two case studies are digital MSPs: Facebook and TopCoder. To emphasize some level of generality of their analysis, they also examine two non-digital platforms: the Roppongi Hills 'mini-city' in Tokyo, Japan, and Harvard Business School.

In Chapter 8, Melissa A. Schilling focuses on the tradeoffs between diffusion and protection of technology platforms. In industries with increasing returns, firms are sometimes encouraged to liberally diffuse their technology platforms (through, for example, open source or liberal licensing arrangements) to increase their likelihood of becoming the dominant design. However, these firms face several dilemmas: if they liberally diffuse the technology to would-be competitors, they relinquish the opportunity to capture monopoly rents when and if their technology emerges as a dominant design. Furthermore, once control of a technology is relinquished, it can be very hard to regain. Finally, liberal diffusion of the technology can result in the fragmentation of the technology platform. These dilemmas raise the following questions: when incompatible technologies compete for the position of dominant design, what factors will determine whether one or more competitors choose to adopt a more 'open' technology strategy? How does a firm decide what level of 'openness' will maximize the technology's chances for survival and the firm's long-term profitability? This chapter systematically examines how either open or closed technologies can rise to the position of dominant design. The conclusions of this chapter help move beyond the appropriability versus open debate by examining the more subtly nuanced benefits of different positions along a 'control continuum', and provide a systematic tool for managers to assess the benefits and costs/risks of adopting a strategy at various points along the control continuum.

In Chapter 9, Shane Greenstein concludes Part II by offering a rich and nuanced essay focusing on the development of commercial Internet, as a unique historical setting allowing in-depth analysis of the relative 
benefits of open versus closed practices. The structure of the commercial Internet cut against the prevailing opinion of many executives in computing and communications in the mid-1990s, which contended that platform leadership from a commercial organization (à la Microsoft and Intel) was necessary for a thriving and growing market. In contrast, the most vocal participants in Internet governance revelled in the freedom of the Internet's development processes, stressing that it placed comparatively fewer restrictions on the flow of technical information. Some even pointed to the PC market as a model of what they were trying to avoid. The debate still persists today about how and why computing platforms thrive with and without commercial leadership. Greenstein's essay illuminates these issues by returning to the first market in which they arose and by re-examining the core issue: what would have been different about the Internet if it had been organized as a proprietary commercial platform? His answer comes in two steps. The first step defines 'open' in the context of the time, namely, comparing Microsoft's development of Windows 95 with similar processes for developing the Internet. The second step examines how three specific features of the Internet might have changed had its processes been less open: the transition from the research-oriented to the commercial Internet; the degree of innovation around the time of the transition; and the events leading to structural change in the commercial Internet market. Greenstein concludes that openness did not do some of the things for which it is often credited, such as make the Internet more innovative. However, he also concludes that openness did play a special role in shaping outcomes in the commercial Internet at this time - in encouraging participation in development of Internet infrastructure and in fostering structural change in the provision of commercial software.

Part III focuses on platform management, design and knowledge issues. It comprises five chapters from authors based in the UK, Italy, France, Sweden and Japan.

In Chapter 10, Mari Sako offers us what will probably become a seminal article on supply chain platforms. Sako's chapter presents an empirically based contribution to the theory of supply chain platforms through an in-depth case study of automotive supplier parks in Brazil. Supplier parks represent a recent template for organizing in the global automotive industry. The template combines outsourcing by automakers and co-location of suppliers on automakers' sites. Sako draws on evidence from three Brazilian supplier parks, Volkswagen Resende, General Motors Gravataí and Ford Camaçari, to analyse the causes and consequences of outsourcing and co-location for the governance of the firm, relations with suppliers, and labour-management relations. She examines three dimensions theoretically and empirically, namely the degree of task outsourcing, the 
pattern of asset ownership and the nature of relational governance. In theory, task modularity facilitates ownership modularity (that is, asset ownership disintegration). But evidence from three major supplier parks in Brazil reveals a diversity of local arrangements, with a negative correlation between task outsourcing and asset outsourcing. This finding is explained by combining insights from the engineering design literature and the organization economics literature. In particular, asset ownership is one of several ways in which control and incentives may be structured. Moreover, the diversity in arrangements is also explained by different combinations of corporate strategy and state policy, as well as by the emergence of different local labour market institutions.

In Chapter 11, Pascal Le Masson, Benoit Weil and Armand Hatchuel explore how industry platforms can be designed using specific collaborative relationships that also take the form of platforms. In several sectors, the architecture of industry is tending to loosen or even disappear: 'smart grids' in electricity supply, biomaterials and home networking in telecommunications and consumer electronics are all examples of new industrial contexts in search of industry platforms. In such situations, who is the industrial architect, i.e., who provides the industry platform? How do platforms emerge and how do companies contribute to the process? The literature insists on the importance of a platform 'core', performing one essential function or solving one essential problem of the system, without investigating how this core can be identified or designed. The authors explore the issues raised by these collaborations for platform design using a multiple case study in four different industries: biomaterials, microelectronics, aeronautics and biotechnologies. In all four cases, a platform design process was followed longitudinally. The authors suggest that the collaborations for platform design consist not only in delivering an industry platform but in positioning this platform potential into a strategic landscape, characterized by alternative platform strategies, the capabilities enabling these platform strategies and the values of these platform strategies for the partners. They suggest that collaborations for platform design have to manage three main processes: (1) value creation, in order to identify a product platform for the industry, but also to evaluate this platform compared to alternatives, and to integrate all possible alternatives into a strategic mapping process; (2) knowledge production and learning by involving partners, offering support for various experiments and providing specific devices for knowledge production; and (3) the interests of each of the partners by simultaneously creating value at the industry level and increasing the value of the partners' assets.

In Chapter 12, Stefano Brusoni and Andrea Prencipe focus on the process of defining new internal platforms. They observe that it is when 
platforms are defined that relationships are established among people and units; new bodies of understanding and practice are generated and old ones discarded; information filters are implemented to selectively retain what is defined as relevant information. The process of defining a new platform is, however, a major and highly risky undertaking in which firms engage very rarely. It is difficult to develop routines and heuristics capable of guiding such activities (exactly because they happen so rarely). Yet any wrong decision taken at this time will have long-lasting effects on firm profitability and eventual survival. The authors argue that the successful introduction of new platforms depends on the implementation of consistent changes across the domains of product, organization and knowledge. In a case study in the aeronautics industry, they find that these changes are implemented by organizations that act as cross-domain catalysts through the mediating role of key people who span all three domains. The aircraft engine industry case illustrates the introduction of a new platform architecture in a high-tech setting. The evidence describes radical changes that revolutionized the products and the manufacturing processes. There were 'make-or-break' decisions that implied the definition of a new 'way of doing things'. Brusoni and Prencipe offer some implications for practice: they argue that key individuals play a fundamental role in enacting cross-domain rewirings. Leading figures that played a central role in the connection of the knowledge, organization and product domains were senior engineers with long careers in the industry. It was their involvement in the minutiae of everyday production that enabled them to cumulatively develop a systemic understanding of technologies, products and the overall industry. This is a major point to consider if one notes how easily manufacturing activities are now being outsourced to low-cost countries.

In Chapter 13, Ramsin Yakob and Fredrik Tell investigate possible approaches to problem solving in product platform development. The ability to manage the problem-solving process is a key capability for reduced product development cycle time. The development of platforms is a complex endeavour requiring the organizing and utilization and involvement of a number of different functional areas of a firm and the inclusion of a variety of expertise, usually in cross-functional development projects. Problems and errors are an inherent part of any development work carried out in such projects. As the complexity of the system increases due to the increasing number of components and interdependences, emerging problems and errors become gradually more difficult to solve. The authors envisage that the more complex the hierarchical configuration of product platforms, the more complex the problems and errors encountered in their development will be. Previous research has distinguished between directional and heuristic problem-solving strategies. The authors discuss 
the appropriateness of these two problem-solving strategies in product platform development projects. The analysis is grounded theoretically as well as in an empirical study of two product platform projects: one in the telecommunications industry and one in the automotive industry. The findings indicate that in developing capabilities for the complex problem solving characteristic of product platform development projects it is paramount to narrow the search process between errors identified and the problem underlying those errors. The successful management of such compression increases the probability of finding remedies for errors, as it reduces the problem landscape in which solutions can be found. For this both heuristic and directional search processes are important.

In Chapter 14, authors Hirofumi Tatsumoto, Koichi Ogawa and Takahiro Fujimoto focus on the effects of technological platforms on the international division of labour. Their chapter focuses on variables such as the characteristics of the platform, the mechanism through which the platform is diffused, and the effect it has on the international division of labour through an architectural analysis of the case of Intel's platform business in Taiwan in the 1990s. The authors define the separation effect of the platform as a mechanism that separates the technologies used in a quasi-modular architecture product into completely modular and integral technologies. The separation effect is derived from the dual nature of the platform: the completely integral architecture inside it and the completely modular architecture outside it. This leads to a difference in the speed of technology diffusion between the finished product level and the platform level, and brings about a production shift of finished products from the developed country to developing countries, while the platform remains in the developed country. With the rapid diffusion of technology, the adoption of a platform leads to a quick expansion of production in developing-country firms. The cost reductions in these firms bring affordable prices and help to create a huge global market, such as the BRIC (Brazil, Russian, India and China) markets. As a result, the platform fundamentally changes the international division of labour by noticeably strengthening the new model of economic collaboration between developing and developed countries. The growth of the platform destroys the advantages of traditional firms in developed countries and encourages entry into the market by new firms in developing countries.

\section{CONCLUDING REMARKS}

This book offers a truly multidisciplinary account of the multifaceted phenomenon of platforms, and it has been a privilege to be part of the 
community of scholars who have contributed to it. This is the outcome of an ambitious programme of international collaboration, but, mostly, all authors join me in hoping that this is just a beginning. We hope this volume will become a reference for students and researchers, and be readable enough for managers who care about the issues of innovation, competition, firms' performance, design and technological development. We hope the insights assembled in this volume will be used as a foundation - dare we say as a platform - for future enquiring minds to improve our responses and uncover new questions. There is much more work to be done. But for now, enjoy your reading!

\section{NOTE}

1. In its 2008 Annual Report Microsoft stated: 'The European Commission closely scrutinizes the design of high-volume Microsoft products and the terms on which we make certain technologies used in these products, such as file formats, programming interfaces, and protocols, available to other companies. In 2004, the Commission ordered us to create new versions of Windows that do not include certain multimedia technologies and to provide our competitors with specifications for how to implement certain proprietary Windows communications protocols in their own products. The Commission's impact on product design may limit our ability to innovate in Windows or other products in the future, diminish the developer appeal of the Windows platform, and increase our product development costs' (emphasis added).

\section{REFERENCES}

Gawer, A. (2000), 'The organization of platform leadership: an empirical investigation of Intel's managerial processes aimed at fostering innovation by third parties', PhD dissertation, MIT Sloan School of Management.

Gawer, A. and M.A. Cusumano (2002), Platform Leadership: How Intel, Microsoft, and Cisco Drive Industry Innovation, Boston, MA: Harvard Business School Press.

Gawer, A. and M. Cusumano (2008), 'How companies become platform leaders', MIT Sloan Management Review, 49 (2), 28-35.

Microsoft (2008), Annual Report, available at http://www.microsoft.com/msft/ reports/ar08/index.html. 